\title{
Influence of Plastic Bottles Fibre on Self Compacting Concrete
}

\author{
Abdelhamed Ganaw*, Basel Meghari, Abdulnasir Alkoum, Mohammed Alawig \\ Department of Civil, College of Engineering, Elmergib University, Libya
}

DOI: https://doi.org/10.21467/proceedings.4.31

* Corresponding author email: engnaw12@gmail.com

\begin{abstract}
It is well known to all of us that water plastic bottles waste has become a major problem to the environment. At the same time, incorporating the fibres in concrete like polypropylene is advantageous as they improve its properties. Nowadays self compacting concrete (SCC) has become very common in casting concrete due to its high flow properties and attained the required strength.

The aim of this research is to study the effect of addition of shredded waste water plastic bottles to the constituents of SCC and comparing the results with those resulted from employing polypropylene fibre available in the market to the mix.

In the study, SCC was produced at constant water content of 0.4 with the addition of constant super-plasticizer of $2 \%$ of cement weight, four fibre contents of $0.05,0.075,0.1$ and 0.125 of the cement weight were employed to the mix, and then fresh and hardened properties of concrete were measured. From the results obtained, it was clearly observed that fresh and hardened properties of SCC can be obtained by using fibres produced from recycled water plastic bottles, and that off course will help in minimizing the pollution of environment.
\end{abstract}

Keywords: Self compacting concrete, polypropylene, plastic bottles and super-plasticizer

\section{Introduction}

Fibre has been used in concrete for many years because of their advantages; they increase concrete strength and sometimes prevent sudden failure in concrete. Natural and manufactured fibres are used in concrete to improve its properties [1]. Natural fibre of plants like Bamboo was added to concrete and resulted in little increase of its compressive strength and higher modulus of elasticity compared with reference concrete [2]. Manufactured fibres have been also used in concrete like, steel, glass, carbon, and Petrochemicals products fibres like polypropylene (PP), polyethylene (PET), polyester and nylon are also used in concrete production industry, and they improve its properties. Steel fibres are the most common fibres used in concrete they are available in the market with different lengths and shapes [3]. For instant, increase of steel fibres addition in concrete from $0.5 \%$ to $2 \%$ by volume resulted in an increase of concrete strength [4]. Moreover, flexure strength of concrete beams was increased by using steel fibres at percentages of $0.75 \%$ and $1.5 \%$ by volume at 7,14 and 28 days [5].

(C) 2018 Copyright held by the author(s). Published by AIJR Publisher in Proceedings of First Conference for Engineering

Sciences and Technology (CEST-2018), September 25-27, 2018, vol. 2 .
This is an open access article under Creative Commons Attribution-NonCommercial 4.0 International (CC BY-NC 4.0) license, which permits any non-commercial use, distribution, adaptation, and reproduction in any medium, as long as the original work is properly cited. ISBN: 978-81-936820-6-7 
Fibre glass was also employed in concrete production at $0.03 \%$ by volume and resulted in an increase of concrete compressive and flexure strength up to $30 \%$ [6]. Polyethylene fibre was used in Indonesia in the production of self compacting concrete (SCC), percentages of up to $0.15 \%$ of mix volume were used in concrete, however flow of concrete was decreased but still in the range and hardened concrete compressive and impact strength were good when fibre added in the range of 0.05 to $0.1 \%$ [7]. Polyethylene shredded fibres from water drinking bottles at slices of $2 * 10 \mathrm{~mm}$ are added to the concrete at 0.16 and $0.325 \%$ of concrete volume, the results of hard concrete showed that compressive and flexure strength have been increased compared with reference concrete[8]. It is obviously that using fibres in concrete generally improves its properties which leads to the need to study both natural and manufactured fibres, moreover study of using of waste materials like drinking water bottles showed good results in concrete production but still a lack of such study on its effect on self compacting concrete, in this research the effect of such fibres on concrete will be done.

\section{Materials Used}

Portland cement used in concrete production was imported from Albourg Factory - Zliten, cement fineness of $3100 \mathrm{~cm}^{2} / \mathrm{g}$, soundness of $1.5 \mathrm{~mm}$ and specific gravity of 3.15 . Its properties were satisfied by British specifications [9]. Water used in this work was drinkable and satisfied by Libyan specifications [10]. Superplasticizer(SP)(Degasetpc7070) from (Yapichem) company was added to concrete mix at $2 \%$ of the cement weight, and its properties are accepted by European specification [11]. The used fine aggregate in the study was also imported From Zliten quarries, its gradation is accepted by the British standards BS 882:1992 [12], and has specific gravity of 2.65 and absorption of 0.0124. Coarse aggregate was imported from local quarry to produce SCC, it was passed from $20 \mathrm{~mm}$ sieve and retained on 14, 10 and $5 \mathrm{~mm}$ sieves, and it was comply to the British standards BS 882:1992 [12]. Coarse aggregate has specific gravity of 2.67 and absorption of 0.0136 . Aggregate gradations, specific gravity and absorption tests were carried out at the Alkhums School of engineering concrete lab. PP fibres (MonofilamentFibres, Sika) are available in the market were used in the study [13], PET fibres were produced from shredding of drinking water bottle, Figures 1 and compared with PP, Figure 2 (They are PET and PP from left to right).

\section{Methodology of the research}

Nine different mix proportions were designed in the study after defining the required water cement ratio $(w / c=0.4)$ ratio and SP required to give high workability for SCC without segregation and that was obtained from experimental work of trial mixes in the lab. The first mix did not contain any fibre, and then PP and PET fibres were employed each at 0.05, 0.075, 0.1 and $0.125 \%$. Fresh concrete first produced by normal mixer in the concrete lab, slump flow test for SCC and J ring tests were carried out according to the British specifications [14, 15], all fresh concrete mixes were able to pass through the bars of J-Ring and gave the required 
Influence of Plastic Bottles Fibre on Self Compacting Concrete

workability for Self compacting concrete. After that concrete was casted in three $100 \mathrm{~mm}$ cubes and three prisms of $400 * 100 * 100 \mathrm{~mm}$ and left in their moulds, no vibration was employed for SCC. After 24 hours concrete samples were extracted from their moulds and left merged in water. Finally, after 28 days, compressive and flexure strengths of SCC were measured.

\section{Results and Discussion}

\subsection{Fresh properties of concrete}

Table 1 shows fresh concrete spread diameter test results of reference and the highest fiber content mixes of $0.125 \%$. It is clear that all mixes are in the range of SCC suggested by the specifications. A decrease of $7.38 \%$ in spread diameter was observed when PP fiber was added and just $4.7 \%$ decrease when PET employed, this result can be attributed to the high surface area of fiber when added to the mix. On the other hand, the increase of $T_{500}$ value when fiber proves that the cohesion and viscosity of concrete is better which prevents concrete segregation. Table 2 shows the results of J-Ring test of fresh concrete. It is obviously that as the fiber added the passing resistance increases from 5.8 up to 9.2, and this is logic because of the effect of fiber which prevents the material from passing easily.

\subsection{Hardened properties concrete}

Figure 3 presents the relation between SCC compressive strength and fiber percentage in the mix. It is clear that as the fiber increases concrete compressive increases until percentage of $0.075 \%$. The same results were obtained in the relation between flexure strength and fiber content as shown in Figure 4. However the trend in both tests started going down the percent of $0.1 \%$ still higher than the reference mix. However PP fiber resulted in higher concrete strength in both tests the difference is very small and can be neglected. These results agreed with other investigations presented in the introduction for normal concrete. Moreover, since this study was carried out on self compacting concrete, this can be considered a good result because SCC needs high flow which still available even the fiber content reached $0.125 \%$.

\subsection{Preparation of Figures and Tables}

Table 1: Slump test results of reference and higher fibre content mixes

\begin{tabular}{|l|c|c|c|c|c|}
\hline Mix & Fibre (\%) & Diameter $(\mathrm{mm})$ & $\begin{array}{l}\text { Specification } \\
(\mathrm{mm})\end{array}$ & $\begin{array}{l}\text { Time } \mathrm{T}_{500} \\
(\mathrm{sec})\end{array}$ & $\begin{array}{l}\text { Specification } \\
(\mathrm{mm})\end{array}$ \\
\hline Reference & 0 & 745 & $650-800$ & 1.9 & $2-5$ \\
\hline PP & 0.125 & 690 & $650-800$ & 2.13 & $2-5$ \\
\hline PET & 0.125 & 710 & $650-800$ & 2.02 & $2-5$ \\
\hline
\end{tabular}

ISBN: 978-81-936820-6-7 
Ganaw et al., CEST-2018, AIJR Proceedings 4, pp.637-642, 2018

Table 2: J-Ring test results of reference and higher fibre content mixes

\begin{tabular}{|l|c|c|l|c|c|c|c|}
\hline Mix & $\begin{array}{l}\text { Fibre } \\
(\%)\end{array}$ & $\begin{array}{l}\text { Diameter } \\
(\mathrm{mm})\end{array}$ & $\begin{array}{l}\text { Specification } \\
(\mathrm{mm})\end{array}$ & $\begin{array}{l}\text { Time } \\
\mathrm{T}_{500} \\
(\mathrm{sec})\end{array}$ & $\begin{array}{l}\text { Specification } \\
(\mathrm{mm})\end{array}$ & $\begin{array}{l}\text { Value } \\
(\mathrm{mm})\end{array}$ & $\begin{array}{l}\text { Specification } \\
(\mathrm{mm})\end{array}$ \\
\hline Ref. & 0 & 710 & $650-800$ & 2.03 & $2-5$ & 5.8 & $0-10$ \\
\hline PP & 0.125 & 665 & $650-800$ & 2.36 & $2-5$ & 9.2 & $0-10$ \\
\hline PET & 0.125 & 680 & $650-800$ & 2.17 & $2-5$ & 9.0 & $0-10$ \\
\hline
\end{tabular}

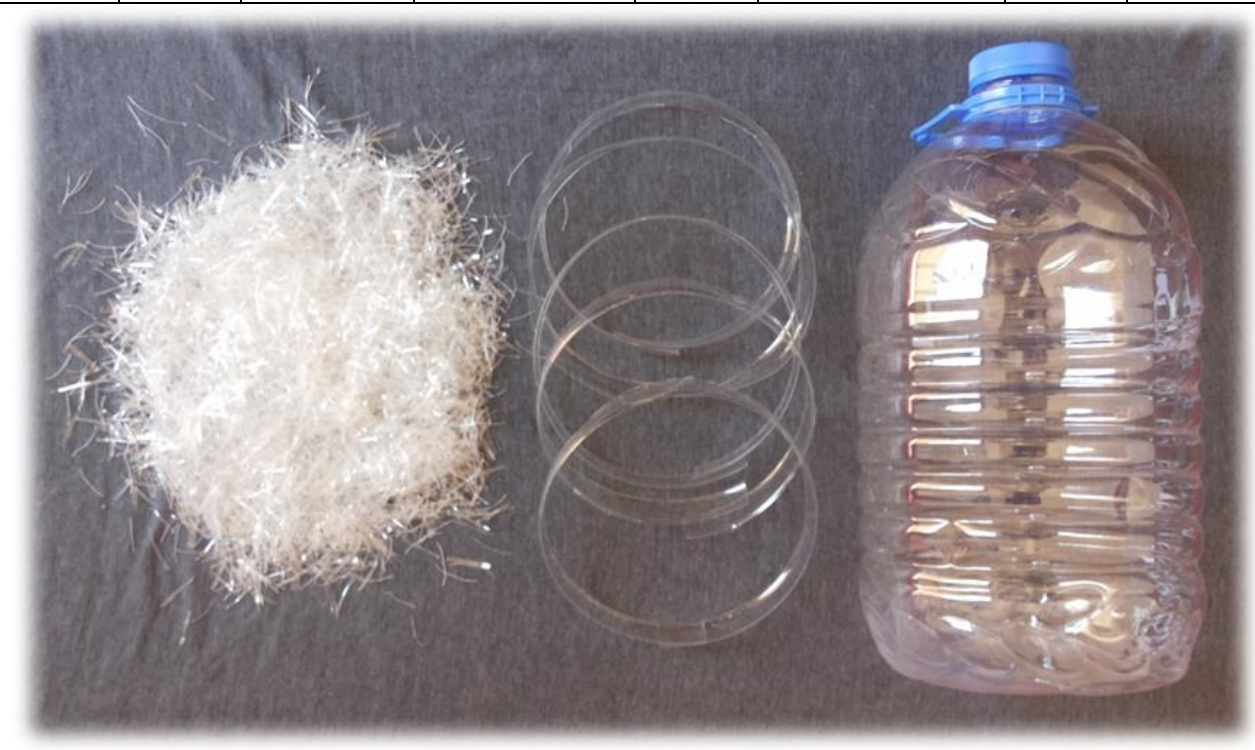

Figure 1: Preparing of PET from plastic bottles

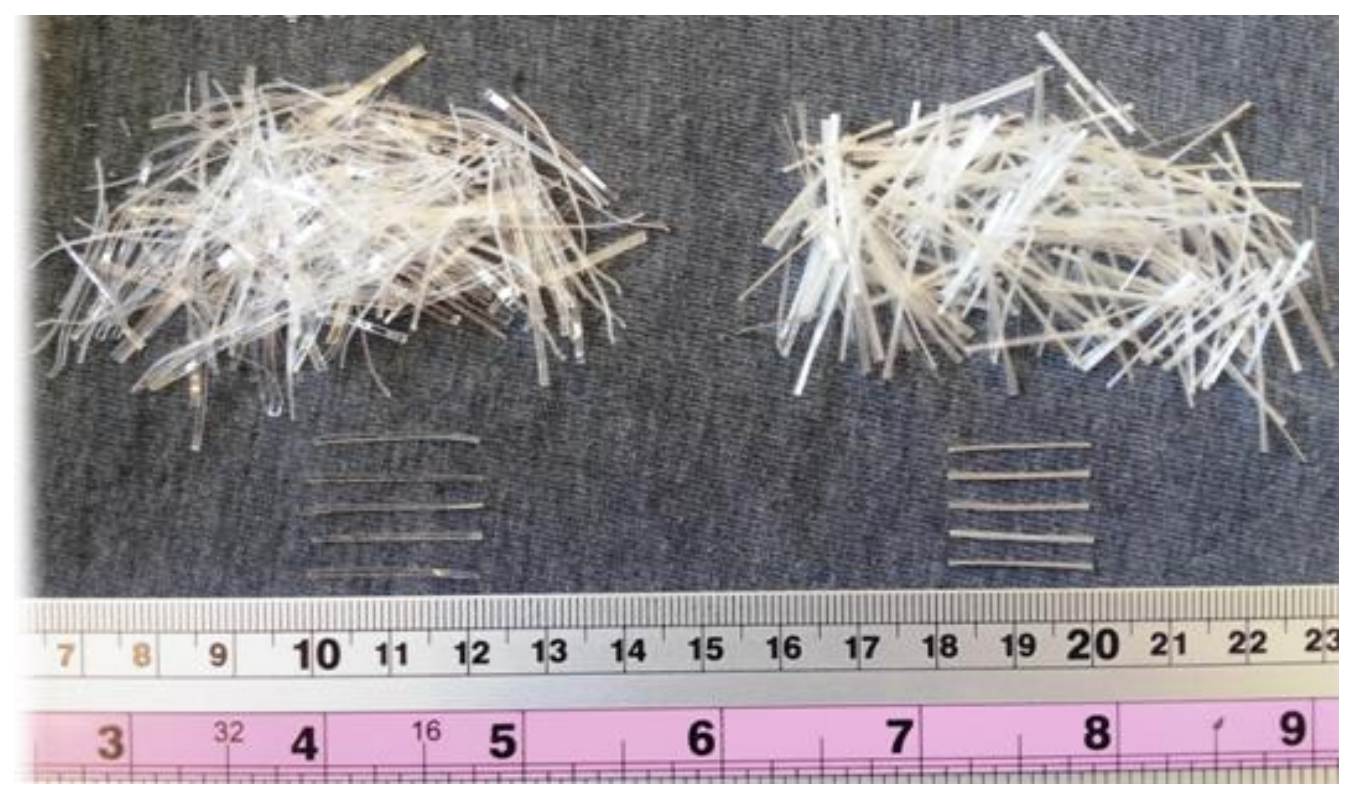

Figure 2: Comparison between PET (left) and PP (right) fibres

Proceedings of First Conference for Engineering Sciences and Technology (CEST-2018), vol. 2 640 
Influence of Plastic Bottles Fibre on Self Compacting Concrete

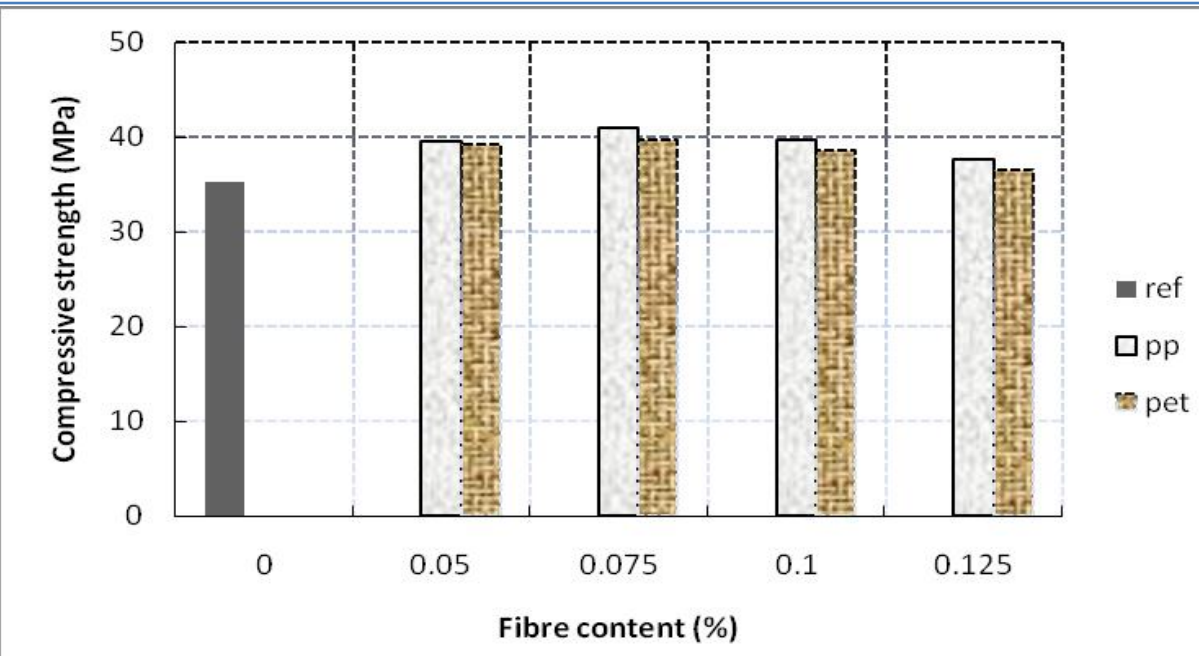

Figure 3: Compressive strength vs. fibre content

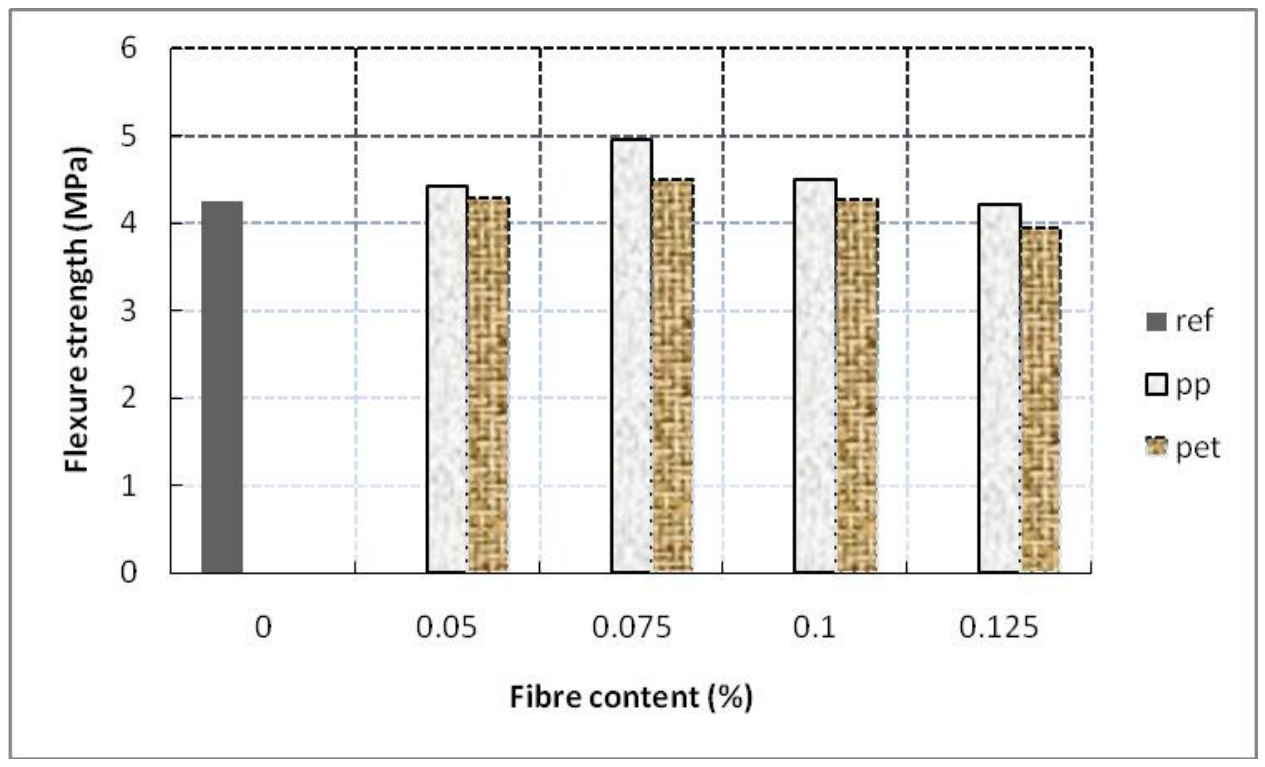

Figure 4: Flexure strength vs. fibre content

\section{Conclusions}

The main objective from the investigation was achieved, as the fibres excluded from waste drinking water bottles resulted in better concrete properties comparing with that of no fibre. Moreover, waste bottles fibres when compared with manufactured fibres available in the market for building objectives resulted in the same results without losing the advantages of self compacting behaviour of fresh concrete. Moreover, recycle of drinking water bottles will result in many advantages, minimizing concrete cost, land areas needed and pollution as this material is not degradable. 


\section{References}

[1] Neville, A. M., "Properties of Concrete," Hand Book, Fifth Edition, Pearson Education Limited, England, 2011.

[2] Ahmad, S. ؛Raza, A. ؛ Gupta, H, "Mechanical Properties of Bamboo Fiber Reinforced Concrete." 2nd international Conference on Research in Science, Engineering and Technology, Dubai-UAE, March, 2014

[3] Grunewald, S. "Performance-based design of self-compacting fiber reinforced concrete," DUP Science, Netherlands, 2004.

[4] Wang, C., "Experimental Investigation on Behavior of Steel Fiber Reinforced Concrete (SFRC)" Master's Thesis in Civil Engineering, the University of Canterbury, New Zealand, 2006

[5] Vairagade, L. N. ؛Bhedi, V. M, "Comparison of Strength between Steel Fiber Reinforced Concrete and Conventional Concrete," International Journal on Recent and Innovation Trends in Computing and Communication, vol. 3, no. 2, pp. 5-10, 2015

[6] Gornale, A. ؛ Quadri, S. I. ؛ Quadri, S. M. ؛ Ali, S. M. ؛ Hussaini, S. S. "Strength Aspects of Glass Fibre Reinforced Concrete.," International Journal of Scientific \& Engineering Research, vol. 3, no. 7, pp. 1-5, 2012.

[7] Widodo, S, "Fresh and Hardened Properties of Polypropylene Fiber Added Self-Consolidating Concrete," International Journal of Civil and Structural Engineering, vol. 3, no. 1, pp. 85-93, 2012

[8] Abdelgader A., Shailan D., "Mechanical properties of polymer concrete contain fibers of waste plastic," Iraqi Journal of Mechanical and Material Engineering, vol. D, no. 1, pp. 653-664. Iraq, 2009.

[9] British Standard Institute, BS EN 197-1 “Cement - Part 1: Composition, specifications and conformity criteria for common cements," London, UK, 2011

[10] Libyan Standard Specification, 294, “Used water in concrete,” Tripoli, 1988

[11] British Standard Institute .BS EN 934-2:2009, "Admixtures for concrete, mortar and grout - Part 2: Concrete admixtures - Definitions, requirements, conformity, marking and labeling,” London, UK, 2012.

[12] British Standard Institute .BS 882:1992, "Specification for aggregates from natural sources for concrete," London, UK, 2002.

[13] Sika Company, Polypropylene Fibers Data Sheet, 2015

[14] British Standard Institute .BS EN 12350-8:2010, "Testing fresh concrete - Part 8: Self-compacting concrete - Slump flow test," London, UK,2010.

[15] British Standard Institute .BS EN 12350-12:2010, "Testing fresh concrete - Part 12: Self-compacting concrete - JRing test," London, UK, 2010. 